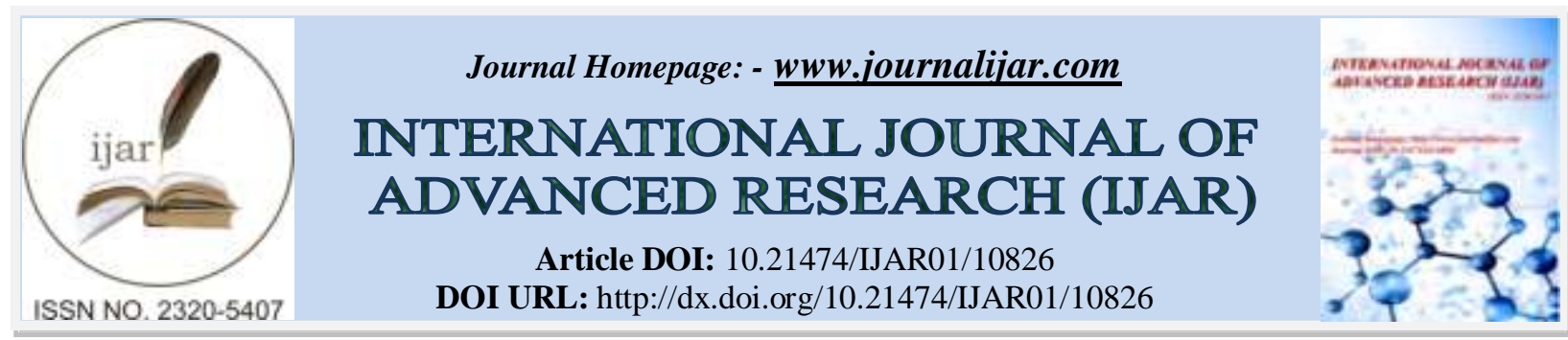

RESEARCH ARTICLE

\title{
A STUDY OF BIOMEDICAL WASTE MANAGEMENT STATUS IN THE URBAN PRIMARY HEALTH CENTRES OF GUWAHATI, ASSAM
}

\author{
Anupjyoti Basistha ${ }^{1}$ and Dr. Mridula Saikia Khanikor ${ }^{2}$ \\ 1. Research Scholar, Department of Allied Health Sciences, Srimanta Sankaradeva University of Health Sciences, \\ Gauhati Medical College Building, Narakasur Hill Top,Bhangagarh,Guwahati-781032, Assam. \\ 2. Indira Gandhi Technological and Medical Sciences University, Ziro, Arunachal Pradesh-791120.
}

\section{Manuscript Info}

Manuscript History

Received: 12 February 2020

Final Accepted: 14 March 2020

Published: April 2020

Key words:-

Biomedical Waste (BMW), Urban

Primary Health Centre(U-PHC)

\section{Abstract}

Biomedical waste (BMW) is generated mainly by health care establishments. The management of BMW is still infant all across the world. According to Biomedical waste management rule 2016 (amended in 2018 \& 2019), the health facilities need to ensure proper segregation of BMW and pre-treat the waste at the facility before disposal/handing over to Common Bio Medical Waste Treatment Facility (CBMWTF). A detailed study on BMW status in Urban Primary Health Centres (U-PHC) of Guwahati was carried out. The study depicts that $85 \%$ of the facilities does have Nodal person to monitor the BMW activities. None of the facility having coloured plastic bin/bags with biohazard symbol, designated waste route, weighing machine and centralized storage area. Collection of BMW by the CBMWTF was average twice a month.

Copy Right, IJAR, 2020,. All rights reserved.

\section{Introduction:-}

'Biomedical waste' means any solid and/or liquid waste including its container and any intermediate product, which is generated during the diagnosis, treatment or immunization of human beings or animals or in research pertaining thereto or in the production or testing thereof.

Clinical consideration is imperative for our life, wellbeing and prosperity. In any case, the waste created from clinical exercises can be dangerous, harmful and even deadly in light of their high potential for ailment transmission. The dangerous and poisonous pieces of waste from human services foundations including irresistible, bio-clinical and radio-dynamic materials just as sharps (hypodermic needles, blades, surgical blades and so forth.) establish a grave hazard, if these are not appropriately treated/arranged or are permitted to get blended in with other metropolitan waste. Its affinity to empower development of different pathogens and vectors and its capacity to pollute different non-hazardous/non-harmful metropolitan waste risks the endeavors embraced for by and large city squander management.The rag pickers and waste workers are often worst affected, because unknowingly or unwittingly, they rummage through all kinds of poisonous materials while trying to salvage items which they can sell for reuse. Simultaneously, this sort of unlawful and unscrupulous reuse can be incredibly hazardous and even deadly. Diseases like cholera, plague, tuberculosis, hepatitis (especially HBV), AIDS (HIV), diphtheria etc. in either pestilence or even endemic structure, present grave general wellbeing dangers. Shockingly, without solid and broad information, it is hard to evaluate the element of the issue or even the degree and assortment of the hazard in question. 


\section{Materials and Methods:-}

The study was conducted over a period of six month. Study was conducted at thirteen (13) U-PHCs of Guwahati, Assam.

A pre-defined observation checklist was developed to monitor the BMW system in the U-PHCs. The author visited all 13 U-PHCs with prior permission from the Medical Officer I/Cs of those UPHCs.

On the day of study , a meeting was called for all staffs and the observation checklist was explained. Also they were explained about the importance of the study. The observation checklist contained 26 closed questions. Information obtained through the observation checklist were analyzed and given below.

\section{Observations:-}

Table 1:-

\begin{tabular}{|l|l|l|l|}
\hline Sl & Observation checkpoints & Yes/Available & No/Not Available \\
\hline 1 & Display of guidelines/chart & $13(100 \%)$ & $0(0 \%)$ \\
\hline 2 & Display of guidelines/chart in waste generation area & $10(77 \%)$ & $3(23 \%)$ \\
\hline 3 & Useful \& readable content of the guideline/chart & $10(77 \%)$ & $3(23 \%)$ \\
\hline 4 & Segregation of waste as per guideline & $10(77 \%)$ & $3(23 \%)$ \\
\hline 5 & Nodal person for monitoring of BMW & $2(15 \%)$ & $11(85 \%)$ \\
\hline
\end{tabular}

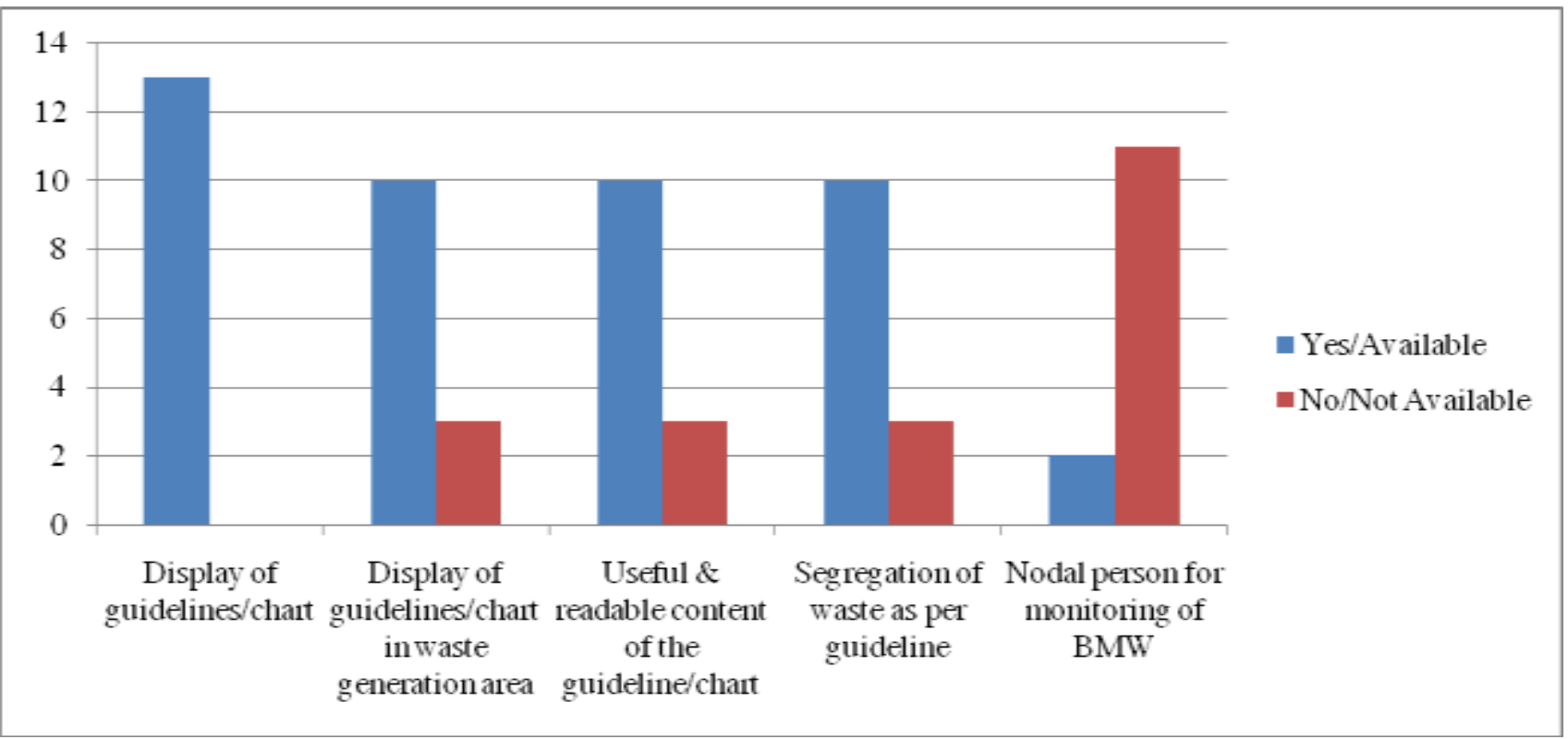

The Biomedical Waste Management system of the 13 U-PHCs was observed and found that the all the UPHCs displayed the guidelines/chart as per BMW rule. Whereas $77 \%$ of the facility displayed it at the source of generation. $23 \%$ of the facilities displayed the guidelines in such a location where no-one reads clearly. The major finding was that out of 13 UPHCs, 3 UPHCs (23\%) segregated the waste wrongly. Also it was found that only 2 facilities (15\%) identified Nodal person to monitor the BMW activity in their facility.

Table 2:-

\begin{tabular}{|l|l|l|l|}
\hline Sl & Observation checkpoints & Yes/Available & No/Not Available \\
\hline 1 & Segregation of waste at generation point & $13(100 \%)$ & $0(0 \%)$ \\
\hline 2 & Appropriate container with plastic at generation point & $13(100 \%)$ & $0(0 \%)$ \\
\hline 3 & Biohazard label on the bags \& bins & $0(0 \%)$ & $13(100 \%)$ \\
\hline 4 & Bags are not more full than 3/4th & $10(77 \%)$ & $3(23 \%)$ \\
\hline 5 & Availability of functional needle destroyer/hub cutter & $13(100 \%)$ & $0(0 \%)$ \\
\hline
\end{tabular}




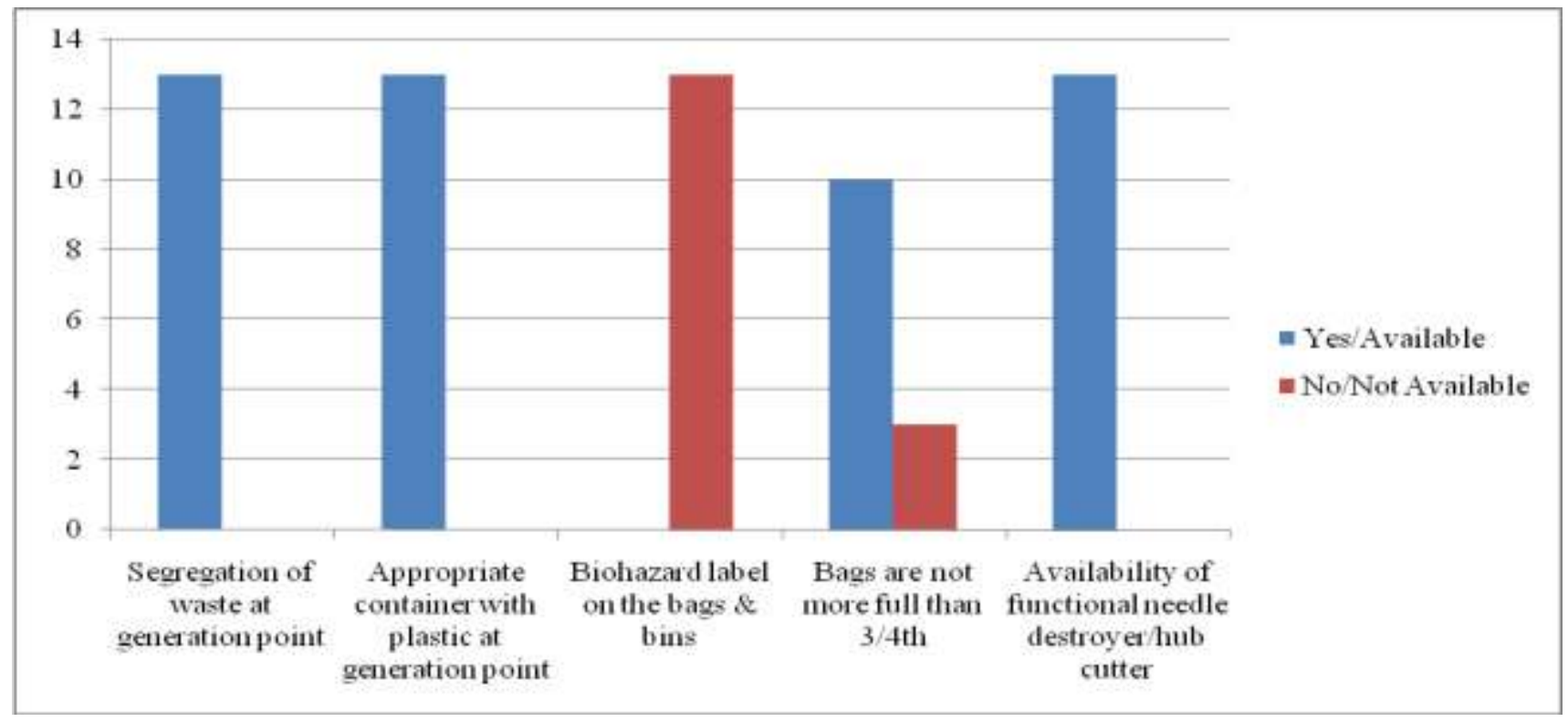

The major finding of the above mentioned checkpoints (Table 2) was that biohazard label on the bags and bins were not found in any of the visited UPHCs.

Table 3:-

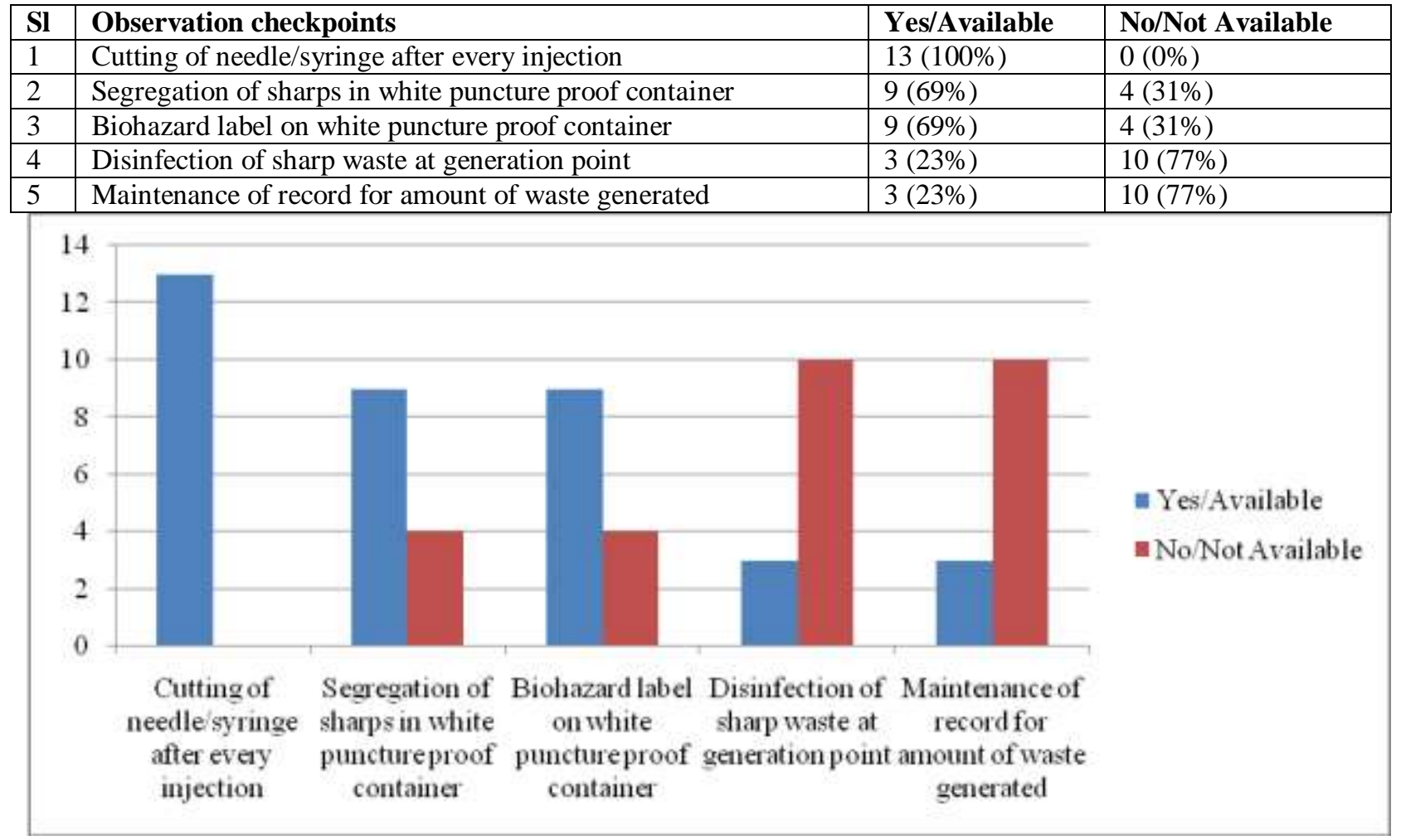

All the UPHCs having functional needle cutter. $69 \%$ of the facility having white puncture proof container kept adjacent to the needle cutter where they put the needles. The most important finding was that $77 \%$ of the facility did not disinfect the sharp waste before disposal/handing over to the CBMWTF. 
Table 4:

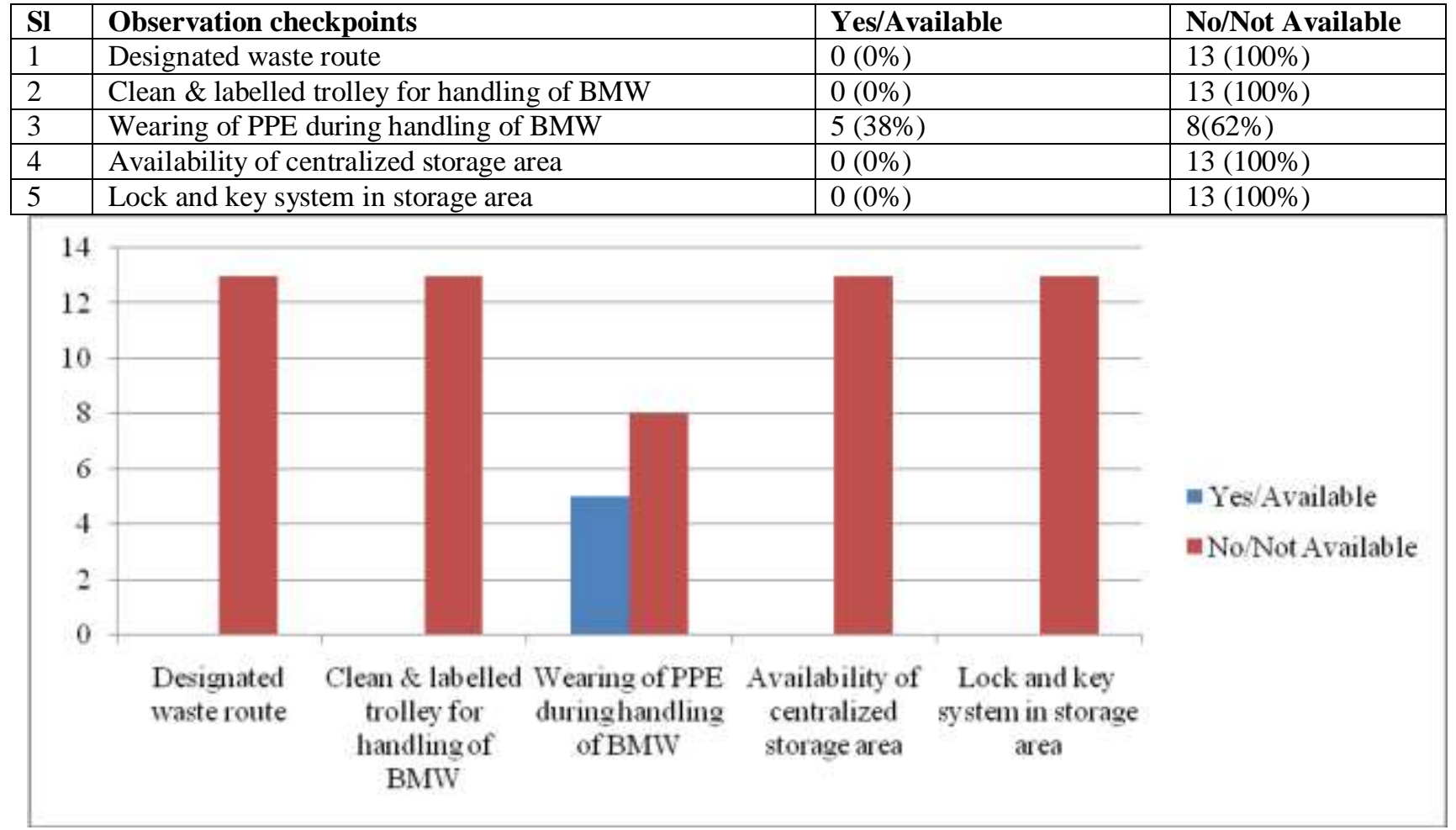

There was no designated rout for BMW found during the visit. Trolley was not available in any of the UPHC for transporting the BMW. Inadequate supply of Personal Protective Equipment was one of the major drawbacks in the system. Centralized storage area for BMW was not available in any UPHCs.

Table 5:-

\begin{tabular}{|l|l|l|l|}
\hline Sl & Observation checkpoints & Yes/Available & No/Not Available \\
\hline 1 & Availability of weighing record & $0(0 \%)$ & $13(100 \%)$ \\
\hline 2 & Designated person for waste storage area & $0(0 \%)$ & $13(100 \%)$ \\
\hline 3 & Separately storage of coloured bags in storage area & $0(0 \%)$ & $13(100 \%)$ \\
\hline 4 & Labelling of bags & $0(0 \%)$ & $13(100 \%)$ \\
\hline 5 & Availability of weighing facility at storage area & $0(0 \%)$ & $13(100 \%)$ \\
\hline 6 & Cleanliness and maintenance of storage area & $0(0 \%)$ & $13(100 \%)$ \\
\hline
\end{tabular}

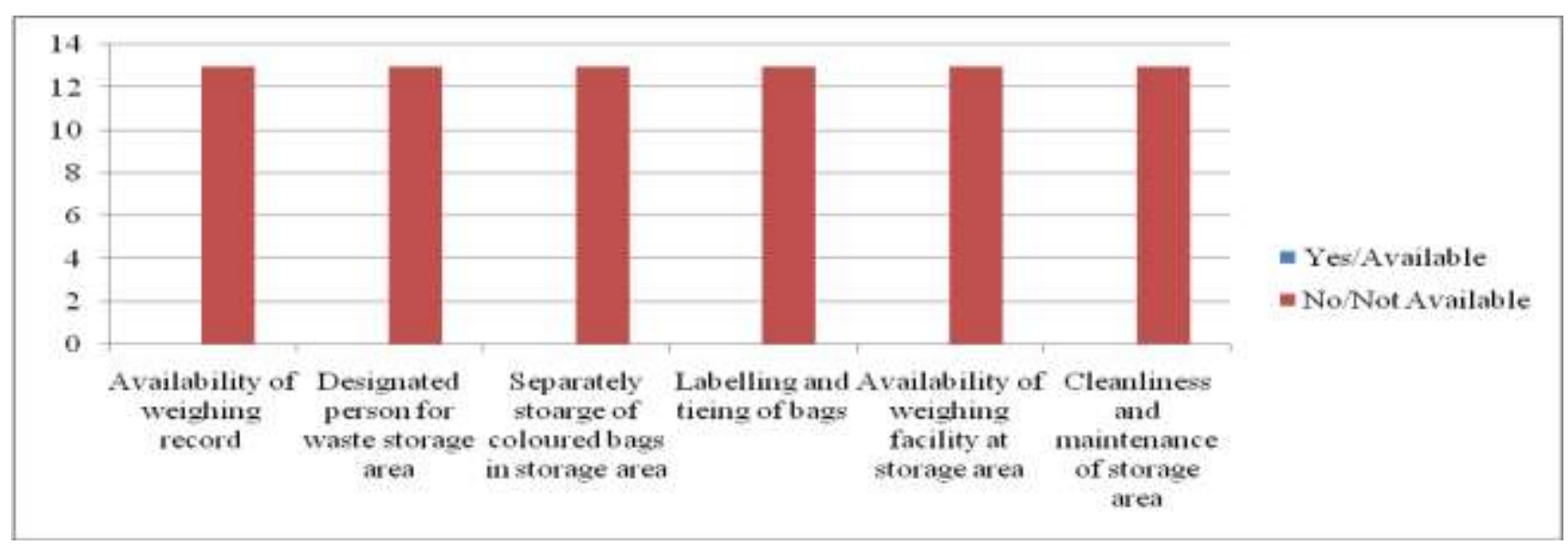


The record of generation of waste, designated person for waste storage area, labeling of bags, weighing machine etc were not available in all of the visited 13 UPHCs.

\section{Major Findings:}

After conducting initial assessment through observation checklist, the following points had come into picture:

1. Nodal person for monitoring of BMW was not available in most of the UPHCs.

2. Biohazard symbol on the bags \& bins not found.

3. Designated route for transporting BMW not evident in all UPHCs.

4. Trolleys for handling of BMW not found in any of the visited facility.

5. There was no Centralized Storage area in all visited UPHCs

6. Weighing machines and weighing records were not available

7. The coloured bags were not labeled.

\section{Recommendation:-}

1. There is an urgent need to identify nodal person for monitoring the day to day BMW activities.

2. Coloured plastic bin/bags with biohazard symbol should be made available.

3. Centralized waste collection area need to be made available with lock \& key system.

4. The generated biomedical waste should be weighed and record need to be kept.

5. Refresher training on Biomedical Waste Management need to be given to all staff.

6. Urgent need of Bio medical waste transport trolley in all the facility.

7. Infection control committee needs to be strengthened.

\section{Reference:-}

1. Tirumala S.Study of Bio-Medical Waste Generation and Managament in Various hospitals in Davangere city of Karnataka,India.NUJHS Vol.3,No.3,Sep 2013,ISSN 2249-7110.

2. Singh Harender,Rehman Rahila,Bumb S Swapnil.Management of Biomedical Waste; A Review.International Journal of dental and Medical research,May-June 2014,Vol 1,Issue 1

3. Dalal Parag.Management of Infectious Bio medical waste of Ujjain City. International Journal of Advanced Research(2013),Vol 1,Issue 2,52-58

4. Dohare S,Garg V K and Sarkar B K.A study of hospital waste management status in health facilties of an urban area. International Journal of Pharma and Bio Sciences.2013 Jan;4(1): (B) 1107-1112

5. AV Tiwari, PA Kadu. Biomedical waste management in India - A Review. Journal of Current Engineering and Technology 2013; 3(5):2030-33.

6. Yadavannavar M, Berad AS, Jagirdar P. Biomedical waste management: a study of knowledge, attitude, and practices in a tertiary health care institution in Bijapur. Indian J Community Med 2010; 35:170-1. 